\title{
One-Pot Synthesis and Strong Near-Infrared Upconversion Luminescence of Poly(acrylic acid)-Functionalized $\mathrm{YF}_{3}: \mathbf{Y b}^{3+} / \mathbf{E r}^{3+}$ Nanocrystals
}

\author{
Leyu Wang ${ }^{1}(\varangle)$, Yi Zhang ${ }^{2}$, and Yanyu Zhu ${ }^{2}$ \\ ${ }^{1}$ State Key Laboratory of Chemical Resource Engineering, Beijing University of Chemical Technology, Beijing 100029, China \\ ${ }^{2}$ College of Chemistry and Materials Science, Anhui Key Laboratory of Chemo-Biosensing, Anhui Normal University, Wuhu 241000, China \\ Received: 24 January 2010 / Revised: 2 March 2010 / Accepted: 3 March 2010 \\ C The Author(s) 2010. This article is published with open access at Springerlink.com
}

\begin{abstract}
This paper describes the synthesis of new upconverting luminescent nanoparticles that consist of $\mathrm{YF}_{3}: \mathrm{Yb}^{3+} / \mathrm{Er}^{3+}$ functionalized with poly(acrylic acid) (PAA). Unlike the upconverting nanocrystals previously reported in the literature that emit visible (blue-green-red) upconversion fluorescence, these as-prepared nanoparticles emit strong near-infrared (NIR, $831 \mathrm{~nm}$ ) upconversion luminescence under $980 \mathrm{~nm}$ excitation. Scanning electron microscopy, transmission electron microscopy, and powder X-ray diffraction were used to characterize the size and composition of the luminescent nanocrystals. Their average diameter was about $50 \mathrm{~nm}$. The presence of the PAA coating was confirmed by infrared spectroscopy. The particles are highly dispersible in aqueous solution due to the presence of carboxylate groups in the PAA coating. By carrying out the synthesis in the absence of $\mathrm{PAA}, \mathrm{YF}_{3}: \mathrm{Yb}^{3+} / \mathrm{Er}^{3+}$ nanorice materials were obtained. These nanorice particles are larger ( $700 \mathrm{~nm}$ in length) than the PAA-functionalized nanoparticles and show strong typical visible red $(668 \mathrm{~nm})$, rather than NIR $(831 \mathrm{~nm})$, upconversion fluorescence. The new PAA-coated luminescent nanoparticles have the pottential be used in a variety of bioanalytical and medical assays involving luminescence detection and fluorescence imaging, especially in vivo fluorescence imaging, due to the deep penetration of NIR radiation.
\end{abstract}

\section{KEYWORDS}

$\mathrm{YF}_{3}$ nanocrystals, NIR upconverting luminescence, poly(acrylic acid)

\section{Introduction}

During the past decades, magnetic nanoparticles [1, 2], noble metal nanocrystals [3], quantum dots (QDs) [4-7], and other kinds of luminescent nanomaterials [8-10] have been successfully prepared and widely used in the biological and medical fields. Due to their novel optical properties, QDs are preferable to organic dyes for biotagging applications. However, their poor biocompatibility and toxic constituents make it a considerable challenge to develop applications of these materials in in vivo imaging [11-13]. Furthermore, the ultraviolet-visible [14] excitation used for QDs and organic dyes will cause damage to biological samples as well as strong autofluorescence, and thus further affect the detection sensitivity when used for in vivo imaging [15-18]. Photon upconversion is an alternative process for the generation of visible

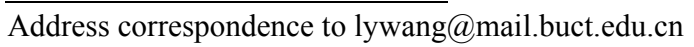


emission (blue-green-red) by near-infrared (NIR) excitation. It is based on sequential photon absorption and energy transfer steps involving real metastable excited states of the chromophore [8, 18-22]. The unique luminescence properties of lanthanide ions incorporated in fluoride matrices have long been recognized and attracted great attention. Recent studies suggest that lanthanide fluorides, including $\mathrm{YF}_{3}, \mathrm{LaF}_{3}$, $\mathrm{NaLaF}_{4}, \mathrm{NaGaF}_{4}$, and $\mathrm{NaYF}_{4}$ nanocrystals are useful upconversion matrices [8, 16, 19, 20, 23, 24]. After doping with $\mathrm{Yb}^{3+} / \mathrm{Er}^{3+}$ or $\mathrm{Yb}^{3+} / \mathrm{Tm}^{3+}$ ion-pairs, the resulting nanocrystals possess novel visible upconversion fluorescence. Their unique upconversion luminescence, especially their novel NIR emission [25, 26], makes these upconversion nanocrystals ideal as biolabels.

In order to increase the optical efficiency of doped nanocrystals, a shell of pure host material has been grown around the core particles to separate the lightemitting ions $\left(\mathrm{Er}^{3+}\right.$ or $\left.\mathrm{Tm}^{3+}\right)$ from solvent molecules and ligands on the nanoparticle surface [27, 28]. Although the existence of high vibrational frequencies resulting from organic surfactants coated on the particle surface will decrease the upconversion emission efficiency, this can sometimes be used to tune the upconversion emission color (green-to-red ratio) [27]. This paper describes a novel strategy to obtain the strong NIR $(831 \mathrm{~nm})$ upconversion emission of $\mathrm{Er}^{3+}$ ions, which has seldom been reported [25]. By using different kinds of surfactants, we obtained $\mathrm{Yb}^{3+} / \mathrm{Er}^{3+}$ doped $\mathrm{YF}_{3}$ nanocrystals with different sizes and upconversion emission colors. The $\mathrm{YF}_{3}: \mathrm{Yb}^{3+} / \mathrm{Er}^{3+} @ \mathrm{PAA}$ nanocrystals obtained using a coating of poly (acrylic acid) (PAA) are of particular interest, as they combine the advantage of strong NIR emission $(831 \mathrm{~nm})$ under NIR $(980 \mathrm{~nm})$ excitation with the advantage of high solubility in aqueous solution associated with the PAA coating. Their novel properties make them complementary to semiconductors and organic dyes currently used in biological and biomedical fields.

Biological tissue strongly absorbs UV radiation and shows strong background fluorescence under UV excitation. NIR radiation, however, shows excellent penetration in in vivo applications and causes no autofluorescence [16-18]. For highly efficient in vivo biolabeling, not only low autofluorescence but also deep optical excitation/emission penetration is very important. So, employing NIR (980 nm) radiation for photon upconversion excitation is preferable for in vivo imaging applications. However, most of the reported upconversion nanocrystals show visible emission, mainly from blue $(470 \mathrm{~nm})$, green $(551 \mathrm{~nm})$ to red $(660 \mathrm{~nm})$ [16-18], and there are few reported materials which emit NIR fluorescence such as $831 \mathrm{~nm}$ light [25]. For materials which emit strong visible fluorescence under $980 \mathrm{~nm}$ excitation, the visible emission is not easy to detect when the particle label is attached to tissues deep inside the animal, which limits their in vivo applications, especially for deep in vivo imaging. In our case, the as-prepared nanocrystals are especially suitable for in vivo imaging due to the deep penetration of NIR emission $(831 \mathrm{~nm})$ and excitation $(980 \mathrm{~nm})$. Furthermore, the materials are biocompatible due to the coating of PAA, as well as nontoxic, in contrast to selenium-containing QDs.

\section{Experimental}

\subsection{Chemicals}

All chemicals were analytical grade and used directly without further purification. $\mathrm{Y}\left(\mathrm{NO}_{3}\right)_{3} \cdot 6 \mathrm{H}_{2} \mathrm{O}$, $\mathrm{Yb}\left(\mathrm{NO}_{3}\right)_{3} \cdot 6 \mathrm{H}_{2} \mathrm{O}, \mathrm{Er}\left(\mathrm{NO}_{3}\right)_{3} \cdot 6 \mathrm{H}_{2} \mathrm{O}, \mathrm{NaF}$, absolute ethanol, and ethylene glycol were obtained from Beijing Ouhe Chemical Reagents Company. Poly(acrylic acid) (PAA, $M_{\mathrm{w}}=1800$, Aldrich), polyethylene glycol (PEG, $M_{\mathrm{w}}=$ 8000, Sigma), and sodium dodecyl sulphonate (SDS, Beijing Chemical Reagents Company) were used as surfactants for the nanoparticle preparation. Deionized water was used throughout.

\subsection{Synthesis of PAA-functionalized $\mathrm{YF}_{3}: \mathrm{Yb}^{3+} / \mathrm{Er}^{3+}$ nanocrystals}

For bioapplications, a primary requirement is to obtain stable, aqueous colloidal dispersions of nanocrystals. This was achieved by a facile one-pot solvothermal method. Luminescent $\mathrm{YF}_{3}: \mathrm{Yb}^{3+} / \mathrm{Er}^{3+} @ \mathrm{PAA}$ nanocrystals were prepared using lanthanide nitrate salts and sodium fluoride as precursors in a mixture of ethylene glycol and ethanol with PAA as the surfactant. In brief, aqueous solutions of $\mathrm{Y}\left(\mathrm{NO}_{3}\right)_{3} \cdot 6 \mathrm{H}_{2} \mathrm{O}$ ( $2.125 \mathrm{~mL}, 0.4 \mathrm{~mol} / \mathrm{L}), \mathrm{Yb}\left(\mathrm{NO}_{3}\right)_{3} \cdot 6 \mathrm{H}_{2} \mathrm{O}(200 \mu \mathrm{L}, 0.5 \mathrm{~mol} / \mathrm{L})$, and $\operatorname{Er}\left(\mathrm{NO}_{3}\right)_{3} \cdot 6 \mathrm{H}_{2} \mathrm{O}(100 \mu \mathrm{L}, 0.05 \mathrm{~mol} / \mathrm{L})$ were added 
to a mixture of ethanol $(20 \mathrm{~mL})$ and ethylene glycol $(10 \mathrm{~mL})$ under magnetic stirring. The sodium fluoride solution $(3 \mathrm{~mL}, 1.0 \mathrm{~mol} / \mathrm{L})$ was then added, and the solution was thoroughly stirred for about $30 \mathrm{~min}$. PAA $(0.1 \mathrm{~g})$ was added to the white colloidal solution and the stirring was maintained for another $30 \mathrm{~min}$. The milky colloidal solution was subsequently transferred into a 50-mL Teflon lined autoclave and heated at $185^{\circ} \mathrm{C}$ for $24 \mathrm{~h}$. Finally, the reaction system was allowed to cool to room temperature. The composition of the resulting nanocrystals is $\mathrm{Y}_{0.85} \mathrm{~F}_{3}: \mathrm{Yb}_{0.1}{ }^{3+} / \mathrm{Er}_{0.05}{ }^{3+} @ \mathrm{PAA}$. The final product was collected by means of centrifugation, washed twice with ethanol, and a third time with deionized water to remove any remaining reactants. The final white product was dispersed in deionized water by ultrasonciation and stored for later use. For X-ray diffraction (XRD) and Fourier transform infrared (FTIR) measurements, the white powder was dried at $100{ }^{\circ} \mathrm{C}$ overnight. In a control experiment, we obtained a nanorice material in the absence of PAA by using the same protocol as above.

\subsection{Characterization}

Transmission electron microscopy (TEM) images were obtained by using a JEOL JEM-1200EX transmission electron microscope with an accelerating voltage of $100 \mathrm{kV}$. A small drop of $\mathrm{YF}_{3}: \mathrm{Yb}^{3+} / \mathrm{Er}^{3+} @$ PAA nanocrystal solution was put on a carbon-coated copper grid. Scanning electron microscopy (SEM) images [29] were obtained using a field-emission scanning electron microscope (Hitachi, S-4800). An X-ray powder diffractometer (Shimadzu, XRD-6000) with $\mathrm{Cu} \mathrm{K \alpha}$ radiation $(\lambda=1.54060 \AA)$ was used to record the XRD patterns of the samples. FTIR spectra were obtained using $\mathrm{KBr}$ pellets and a Nicolet-560 spectrophotometer. The fluorescence emission spectra were obtained on a Hitachi F-4500 fluorescence spectrophotometer with a $980 \mathrm{~nm}$ laser diode as the excitation source.

\section{Result and discussion}

\subsection{SEM and TEM images of the as-prepared nanocrystals}

Figure 1 shows SEM images of the $\mathrm{YF}_{3}: \mathrm{Yb}^{3+} / \mathrm{Er}^{3+} @ \mathrm{PAA}$ nanocrystals (a) and the $\mathrm{YF}_{3}: \mathrm{Yb}^{3+} / \mathrm{Er}^{3+}$ nanorice (b). The $\mathrm{YF}_{3}: \mathrm{Yb}^{3+} / \mathrm{Er}^{3+} @ \mathrm{PAA}$ nanocrystals (Fig. 1(a)) have a high degree of uniformity with a narrow dispersion

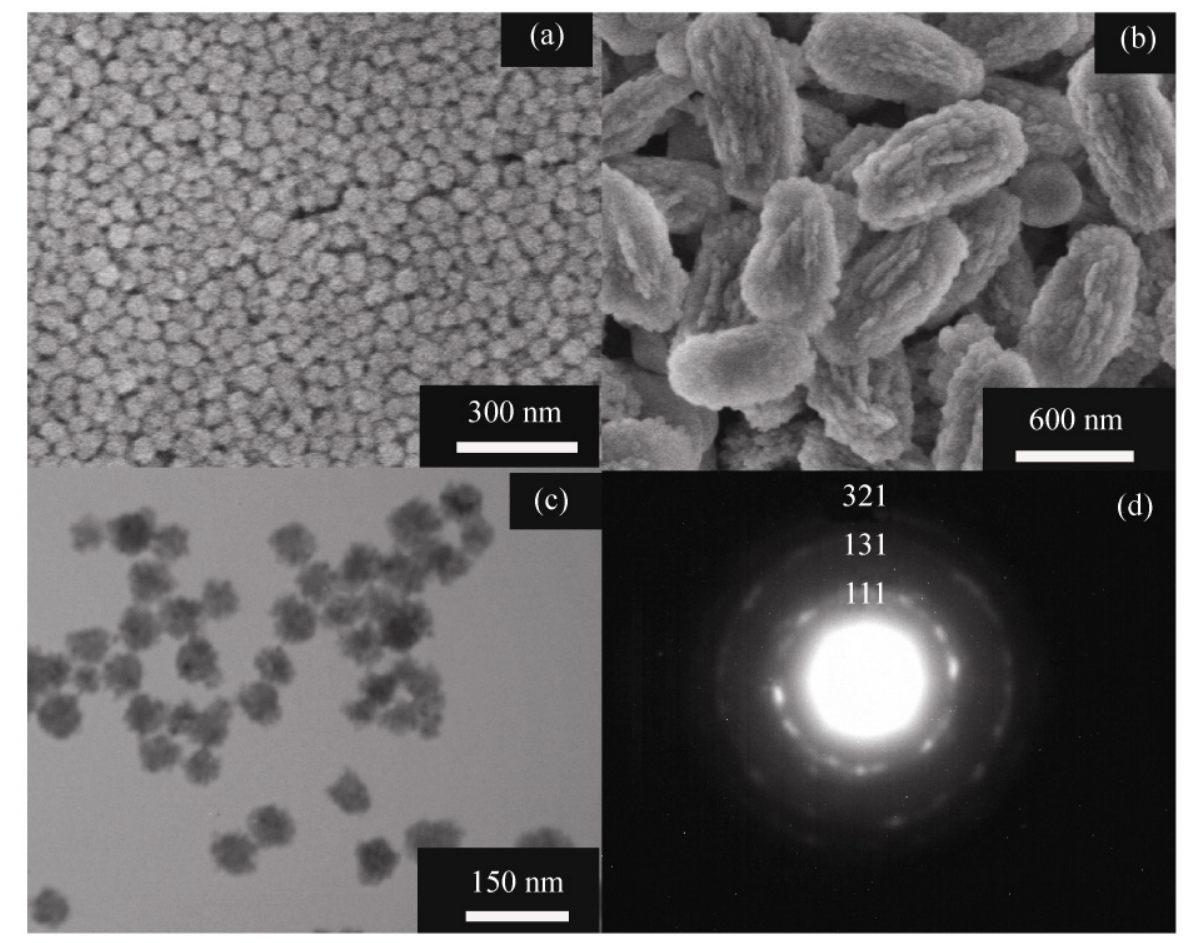

Figure 1 SEM (a) and (b) and TEM (c) images of the PAA-coated $\mathrm{YF}_{3}: \mathrm{Yb}^{3+} / \mathrm{Er}^{3+}$ nanoparticles (a) and (c) and uncoated $\mathrm{YF}_{3}: \mathrm{Yb}^{3+} / \mathrm{Er}^{3+}$ nanorice (b). (d) Electron diffraction pattern of the PAA-coated $\mathrm{YF}_{3}: \mathrm{Yb}^{3+} / \mathrm{Er}^{3+}$ nanoparticles shown in (c) 
of particle size. Comparison of the image in Fig. 1(a) with that in Fig. 1(b) indicates that very different particles are produced by the same method of preparation in the presence (Fig. 1(a)) and absence (Fig. 1(b)) of PAA. In the absence of PAA as the surfactant, only large ( 700 nm in length) nanorice particles were obtained instead of nanoparticles. The size difference is presumably caused by the strong chelating interaction between the lanthanide ions and the carboxylate groups in PAA. Due to this strong chelating effect, the lanthanide ions do not readily react with fluoride anions. After crystal seeds were formed in the initial reaction phase, PAA became coated onto the outer surface of the nanoparticles and consequently prevented the nanocrystals from growing to a large size. As a result, only small nanoparticles were obtained in the presence of PAA. However, in the absence of PAA, the particles had nothing coating their surface to limit their growth and finally grew to very large sizes. Figure 1(c) shows a TEM image of the sample prepared in the presence of PAA. The TEM image confirms the uniform shape and narrow size dispersion of the particles, with an average size of about $50 \mathrm{~nm}$. The TEM image suggests that PAA is uniformly packed on the surface of $\mathrm{YF}_{3}: \mathrm{Yb}^{3+} / \mathrm{Er}^{3+}$ nanocrystals resulting in their uniform shape. From the SEM and TEM images, it is clear that both the nanoparticles and the nanorice particles are composed of small nanocrystals. The difference is that the size of these nanocrystals is larger for the nanorice than for the PAA-coated nanoparticles, because the crystal seeds are not able to grow very large in the presence of PAA due to the strong chelating interaction between the carboxylate and lanthanide ions. Although the-PAA coated nanoparticles consist of small nanocrystals, the electron diffraction pattern (Fig. 1(d)) demonstrates their good crystallinity and is consistent with the expected pattern for cubic $\mathrm{YF}_{3}$.

\subsection{XRD characterization of the $\mathrm{YF}_{3}$ nanocrystals}

Both the nanorice and PAA-coated nanoparticles were also characterized by powder XRD. The XRD patterns of $\mathrm{YF}_{3}: \mathrm{Yb}^{3+} / \mathrm{Er}^{3+} @ \mathrm{PAA}$ nanoparticles and $\mathrm{YF}_{3}: \mathrm{Yb}^{3+} / \mathrm{Er}^{3+}$ nanorice are depicted in Fig. 2. The peak positions and relative intensities for both nanoparticles and nanorice are in good agreement with the literature values for the 111, 201, 131, 321, 322, 341, and 223 reflections of the cubic phase structure of $\mathrm{YF}_{3}$ (JCPDS 74-0911) [19]. A large number of weaker peaks are also seen in the pattern of the nanorice which are not observed in the pattern of the $\mathrm{YF}_{3}: \mathrm{Yb}^{3+} / \mathrm{Er}^{3+} @ \mathrm{PAA}$ nanoparticles, consistent with the larger crystallite size of the former. The XRD patterns in Fig. 2 are therefore consistent with the electron diffraction pattern shown in Fig. 1(d), and confirm that the $\mathrm{YF}_{3}: \mathrm{Yb}^{3+} / \mathrm{Er}^{3+} @ \mathrm{PAA}$ nanoparticles have the cubic $\mathrm{YF}_{3}$ structure. In addition to the aforementioned particle sizes of 50 and $700 \mathrm{~nm}$ estimated from TEM and SEM images, respectively, we also can calculate the particle size using the Scherrer formula based on the broadening of the XRD peaks. However, when the particle size is over $50 \mathrm{~nm}$, such calculations are not very accurate. Therefore, we have only calculated the size of the PAA-coated nanoparticles via the Scherrer formula. The calculated size is about $43.5 \mathrm{~nm}$, which is slightly less than that suggested by the TEM images, which is reasonable because the nanoparticles shown in the TEM images are composed of smaller crystals.

\subsection{FTIR characterization of the as-prepared nanocrystals}

Due to the presence of the carboxylate groups in the PAA coating on the nanoparticle surface, the $\mathrm{YF}_{3}: \mathrm{Yb}^{3+}$ / $\mathrm{Er}^{3+} @$ PAA nanocrystals possess excellent dispersibility

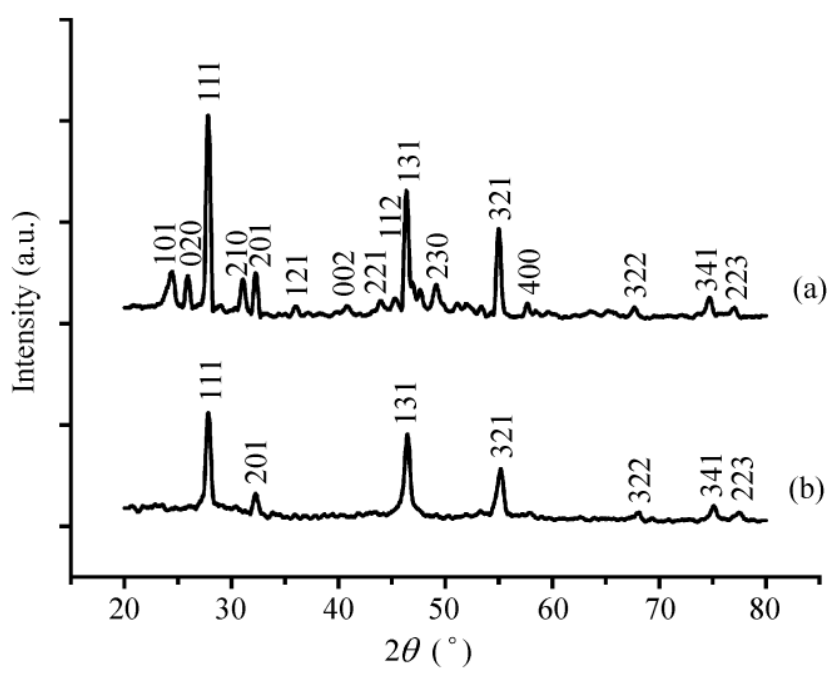

Figure $2 \mathrm{XRD}$ patterns of $\mathrm{YF}_{3}: \mathrm{Yb}^{3+} / \mathrm{Er}^{3+}$ nanorice (a) and $\mathrm{YF}_{3}: \mathrm{Yb}^{3+} / \mathrm{Er}^{3+} @$ PAA nanoparticles (b) 
in aqueous solution, as required for biological and biomedical applications. The PAA coating can be easily characterized by FTIR spectroscopy. Figure 3 shows the FTIR spectra of $\mathrm{YF}_{3}: \mathrm{Yb}^{3+} / \mathrm{Er}^{3+}$ nanorice and $\mathrm{YF}_{3}: \mathrm{Yb}^{3+} / \mathrm{Er}^{3+} @ \mathrm{PAA}$ nanoparticles. The absorption around $3441 \mathrm{~cm}^{-1}$ in the spectrum of the nanorice without a PAA coating (Fig. 3(a)) is assigned to $\mathrm{O}-\mathrm{H}$ vibrations resulting from ethylene glycol or ethanol adsorbed on the $\mathrm{YF}_{3}$ surface during the preparation process. The absorption peak around $1629 \mathrm{~cm}^{-1}$ can be attributed to the $\mathrm{Y}-\mathrm{O}$ vibration in impurities caused by the presence of $\mathrm{O}_{2}$ during the reaction. The strong peak at $468 \mathrm{~cm}^{-1}$ results from the $\mathrm{Y}-\mathrm{F}$ vibrations. In the spectrum of $\mathrm{YF}_{3}: \mathrm{Yb}^{3+} / \mathrm{Er}^{3+} @ \mathrm{PAA}$ nanoparticles (Fig. 3(b)), the broad and strong stretching vibration band centered at $3491 \mathrm{~cm}^{-1}$ is characteristic of $\mathrm{O}-\mathrm{H}$ in a $-\mathrm{COOH}$ group, and the peak at $2952 \mathrm{~cm}^{-1}$ is attributed to the methylene $\left(\mathrm{CH}_{2}\right)$ stretching vibrations of the long alkyl chain of PAA. The band at $1728 \mathrm{~cm}^{-1}$ is assigned to the $\mathrm{C}=\mathrm{O}$ stretching vibration of the $-\mathrm{COOH}$ group, and the bands at 1571 and $1461 \mathrm{~cm}^{-1}$ result from the asymmetric and symmetric stretching vibrations, respectively, of the carboxylate group $\left(-\mathrm{COO}^{-}\right)$in the PAA coating. The peak at $1422 \mathrm{~cm}^{-1}$ is due to the $\mathrm{C}-\mathrm{O}$ stretching vibration in the $-\mathrm{COOH}$ groups of PAA. The significant differences between the spectra in Figs. 3(a) and 3(b) confirm that the nanocrystals have been surface-modified by PAA in the latter case.

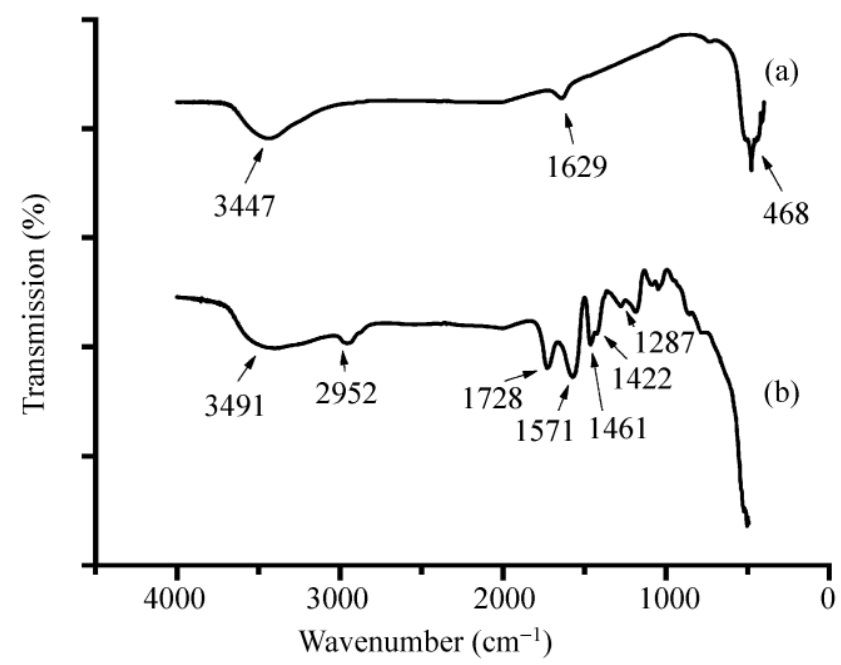

Figure 3 FTIR spectra of the $\mathrm{YF}_{3}: \mathrm{Yb}^{3+} / \mathrm{Er}^{3+}$ nanorice without PAA coating (a) and $\mathrm{YF}_{3}: \mathrm{Yb}^{3+} / \mathrm{Er}^{3+} @$ PAA nanoparticles (b)
3.4 Upconversion luminescence spectra of $\mathrm{YF}_{3}$ : $\mathrm{Yb}^{3+} / \mathrm{Er}^{3+}$ nanorice and $\mathrm{YF}_{3}: \mathrm{Yb}^{3+} / \mathrm{Er}^{3+} @ \mathrm{PAA}$ nanoparticles

The novel upconversion luminescence for both $\mathrm{YF}_{3}$ : $\mathrm{Yb}^{3+} / \mathrm{Er}^{3+}$ nanorice and $\mathrm{YF}_{3}: \mathrm{Yb}^{3+} / \mathrm{Er}^{3+} @ \mathrm{PAA}$ nanoparticles is demonstrated in Fig. 4. The emission peaks of $\mathrm{YF}_{3}: \mathrm{Yb}^{3+} / \mathrm{Er}^{3+}$ nanorice (Fig. 4(b)) are located at $551 \mathrm{~nm}$ $\left(\mathrm{Er}^{3+}:{ }^{4} \mathrm{~S}_{3 / 2} \rightarrow{ }^{4} \mathrm{I}_{15 / 2}\right), 668 \mathrm{~nm}\left(\mathrm{Er}^{3+}:{ }^{4} \mathrm{~F}_{9 / 2} \rightarrow{ }^{4} \mathrm{I}_{15 / 2}\right)$ [19], and $831 \mathrm{~nm}\left(\mathrm{Er}^{3+}:{ }^{4} \mathrm{~S}_{3 / 2} \rightarrow{ }^{4} \mathrm{I}_{13 / 2}\right)$ [25]. The main emission centered at $668 \mathrm{~nm}$ is so strong that a very strong red luminescence in $\mathrm{YF}_{3}: \mathrm{Yb}^{3+} / \mathrm{Er}^{3+}$ is visible to the naked eye when a colloidal solution of the nanorice is irradiated at $980 \mathrm{~nm}$ with a laser diode. Although the red emission of $\mathrm{YF}_{3}: \mathrm{Yb}^{3+} / \mathrm{Er}^{3+}$ nanorice is very strong, the NIR emission at $831 \mathrm{~nm}$ is rather weak. Unlike the $\mathrm{YF}_{3}: \mathrm{Yb}^{3+} / \mathrm{Er}^{3+}$ nanorice, the $\mathrm{YF}_{3}: \mathrm{Yb}^{3+} / \mathrm{Er}^{3+} @ \mathrm{PAA}$ nanoparticles (Fig. 4(a)) show very weak blue emission at $417 \mathrm{~nm}$ and $488 \mathrm{~nm}$. As shown in Fig. 4(a), these peaks can be assigned to the $\mathrm{Er}^{3+}:{ }^{2} \mathrm{H}_{9 / 2} \rightarrow{ }^{4} \mathrm{I}_{15 / 2}$ and $\mathrm{Er}^{3+}$ : ${ }^{4} \mathrm{~F}_{7 / 2} \rightarrow{ }^{4} \mathrm{I}_{15 / 2}$ transitions, respectively. It should be noted that such relatively weak blue emissions at 417 and $488 \mathrm{~nm}$ have seldom been reported [30]. The expected green emission at $551 \mathrm{~nm}$ and red emission at $668 \mathrm{~nm}$, however, are too weak to be seen in the fluorescence spectra. It should be noted that the NIR upconversion luminescence at $831 \mathrm{~nm}$ is relatively strong. To the best of our knowledge, this NIR emission has seldom been previously reported for the $\mathrm{Er}^{3+}$ ion in the literature.

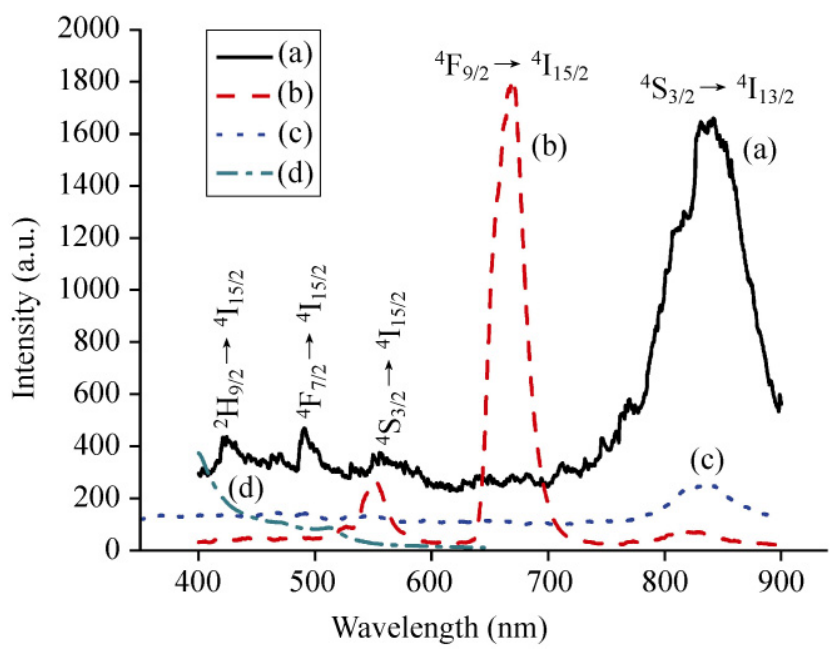

Figure 4 Upconversion luminescence spectra of (a) $\mathrm{YF}_{3}$ : $\mathrm{Yb}^{3+} / \mathrm{Er}^{3+}$ (PAA nanoparticles, (b) $\mathrm{YF}_{3}: \mathrm{Yb}^{3+} / \mathrm{Er}^{3+}$ nanorice, and (c) $\mathrm{YF}_{3}: \mathrm{Er}^{3+} @$ PAA nanoparticles under $980 \mathrm{~nm}$ laser excitation; (d) downconversion luminescence spectrum of $\mathrm{YF}_{3}: \mathrm{Er}^{3+} @ \mathrm{PAA}$ nanoparticles under $345 \mathrm{~nm}$ excitation 


\subsection{Influence of $\mathrm{Yb}^{3+}$ ions on the upconversion luminescence of the nanocrystals}

In order to investigate the luminescence under direct $\mathrm{Er}^{3+}$ excitation, we also prepared nanocrystals doped only with $\mathrm{Er}^{3+}$ using the same protocol employed for $\mathrm{YF}_{3}: \mathrm{Yb}^{3+} / \mathrm{Er}^{3+} @ \mathrm{PAA}$ nanoparticles. Not only the downconversion but also the upconversion emission of the as-prepared $\mathrm{YF}_{3}: \mathrm{Er}^{3+} @ \mathrm{PAA}$ nanoparticles was investigated. The visible emission spectrum under $345 \mathrm{~nm}$ excitation, depicted in Fig. 4(d), shows that no significant emission was observed. Figure 4(c) shows the NIR upconversion luminescence under $980 \mathrm{~nm}$ excitation and indicates that the emission intensity of $\mathrm{YF}_{3}: \mathrm{Er}^{3+} @ \mathrm{PAA}$ nanoparticles is far weaker than that of $\mathrm{YF}_{3}: \mathrm{Yb}^{3+} / \mathrm{Er}^{3+} @ \mathrm{PAA}$ nanoparticles. We also prepared $\mathrm{YF}_{3}: \mathrm{Er}^{3+}$ nanoparticles without $\mathrm{Yb}^{3+}$ codoping in the presence of other surfactants such as SDS and PEG. The upconversion emissions of these two kinds of nanoparticles were studied under $980 \mathrm{~nm}$ excitation. No NIR emission was observed around $831 \mathrm{~nm}$, but a rather weak red fluorescence centered at $668 \mathrm{~nm}$ was observed (spectra not shown). These results indicate that the $\mathrm{Yb}^{3+}$ ion is a relatively efficient energy donor for the $\mathrm{Yb}^{3+} / \mathrm{Er}^{3+}$ ion-pair NIR upconversion luminescence.

\subsection{Influence of surfactants on the upconversion luminescence}

In order to understand the mechanism responsible for the novel NIR emission observed above, we also prepared $\mathrm{YF}_{3}: \mathrm{Yb}^{3+} / \mathrm{Er}^{3+}$ nanoparticles with similar sizes by using different surfactants via the same protocol used for PAA. The sizes of all the nanoparticles coated with different kinds of surfactants are around $50 \mathrm{~nm}$, and their SEM images are shown in Fig. S-1 in the Electronic Supplementary Material (ESM). Their upconversion emission spectra are depicted in Fig. 5. Although the particle sizes are similar, the luminescence properties are quite different. A very weak NIR $(831 \mathrm{~nm})$ upconversion emission is observed for the nanoparticles prepared at the presence of PEG. However, the red upconversion luminescence located at $668 \mathrm{~nm}$ is very strong in the case of this material. For the SDS-coated nanoparticles, emissions at both $668 \mathrm{~nm}$ and $831 \mathrm{~nm}$ are observed, and the intensity

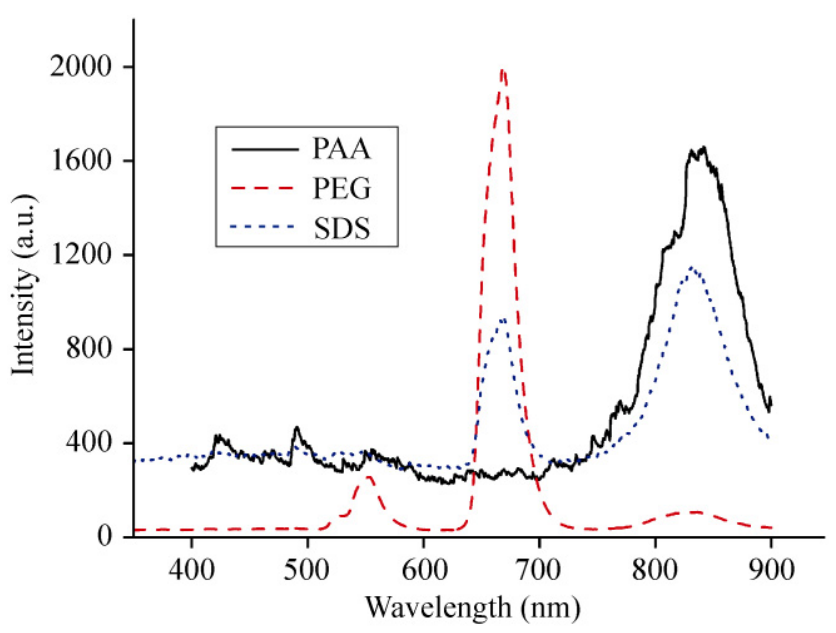

Figure 5 Upconversion luminescence spectra of $\mathrm{YF}_{3}: \mathrm{Yb}^{3+} / \mathrm{Er}^{3+}$ nanoparticles coated with PAA (solid line), PEG (dashed line), and SDS (dotted line). The average size of the nanoparticles coated with the different surfactants is around $50 \mathrm{~nm}$ in each case

ratio $I_{831 / 668}$ is about 1.2. In contrast, the PAA-coated nanoparticles show rather strong NIR $(831 \mathrm{~nm})$ upconversion luminescence and no emission around $668 \mathrm{~nm}$ can be seen. These results indicate that the NIR emission is probably associated with novel surface properties rather than particle size.

\subsection{Upconversion luminescence mechanism of the nanocrystals}

In order to better understand the mechanism of upconversion emission, the upconversion excitation pathways for the $\mathrm{Yb}^{3+} / \mathrm{Er}^{3+}$ ion-couple are depicted in Fig. 6. An initial energy transfer from a $\mathrm{Yb}^{3+}$ ion in the ${ }^{2} \mathrm{~F}_{7 / 2}$ state to an $\mathrm{Er}^{3+}$ ion populates the ${ }^{4} \mathrm{I}_{15 / 2}$ level. Then another $980 \mathrm{~nm}$ photon, or energy transfer from a $\mathrm{Yb}^{3+}$ ion, can populate the ${ }^{4} \mathrm{~F}_{7 / 2}$ level of the $\mathrm{Er}^{3+}$ ion. The $\mathrm{Er}^{3+}$ ions can then relax without emission to the ${ }^{2} \mathrm{H}_{11 / 2}$ and ${ }^{4} S_{3 / 2}$ levels. The green emission bands at $551 \mathrm{~nm}$ and $525 \mathrm{~nm}$ can be attributed to the $\mathrm{Er}^{3+}:{ }^{4} \mathrm{~S}_{3 / 2} \rightarrow{ }^{4} \mathrm{I}_{15 / 2}$ and $\mathrm{Er}^{3+}:{ }^{2} \mathrm{H}_{11 / 2} \rightarrow{ }^{4} \mathrm{I}_{15 / 2}$ transitions, respectively. Because of the short lifetime of the ${ }^{4} \mathrm{I}_{11 / 2}$ level, some ions in this level will decay nonradiatively to the long-lived ${ }^{4} \mathrm{I}_{13 / 2}$ level, and then be excited to the ${ }^{4} \mathrm{~F}_{9 / 2}$ level via energy transfer from excited $\mathrm{Yb}^{3+}$ ions. Thus, the red emission at $668 \mathrm{~nm}$ can be obtained when the $\mathrm{Er}^{3+}$ ion at ${ }^{4} \mathrm{~F}_{9 / 2}$ state relaxes to the ground state $\left({ }^{4} \mathrm{I}_{15 / 2}\right)$. The $831 \mathrm{~nm}$ emission can be obtained via multiphoton energy transfer, and shows relatively strong luminescence in the 
near-infrared region. This emission results from the ${ }^{4} S_{3 / 2} \rightarrow{ }^{4} I_{13 / 2}$ transition [25]. The blue emissions centered at $417 \mathrm{~nm}$ and $488 \mathrm{~nm}$ can be assigned to $\mathrm{Er}^{3+}$ : ${ }^{2} \mathrm{H}_{9 / 2} \rightarrow{ }^{4} \mathrm{I}_{15 / 2}$ and $\mathrm{Er}^{3+}:{ }^{4} \mathrm{~F}_{7 / 2} \rightarrow{ }^{4} \mathrm{I}_{15 / 2}$ transitions, respectively $[19,30]$. As shown in Fig. 4, the upconversion emission of $\mathrm{YF}_{3} @ \mathrm{PAA}$ nanoparticles doped with only $\mathrm{Er}^{3+}$ is far weaker than that of $\mathrm{Yb}^{3+} / \mathrm{Er}^{3+}$ ion-pair doped $\mathrm{YF}_{3} @ \mathrm{PAA}$ nanoparticles. This indicates that the luminescence efficiency of direct $\mathrm{Er}^{3+}$ excitation is too low, confirming that the NIR emission is mainly due to the $\mathrm{Yb}^{3+} \rightarrow \mathrm{Er}^{3+}$ energy transfer process as depicted in Fig. 6.

In order to further understand the upconversion mechanism in these as-prepared nanoparticles, the intensities of the upconversion emissions were recorded as a function of the $980 \mathrm{~nm}$ excitation intensity. At low excitation power density, the output intensity $\left(I_{\mathrm{o}}\right)$ will be proportional to some power $(n)$ of the infrared excitation $\left(I_{\mathrm{IR}}\right)$ power. The value of $n$ is the number of

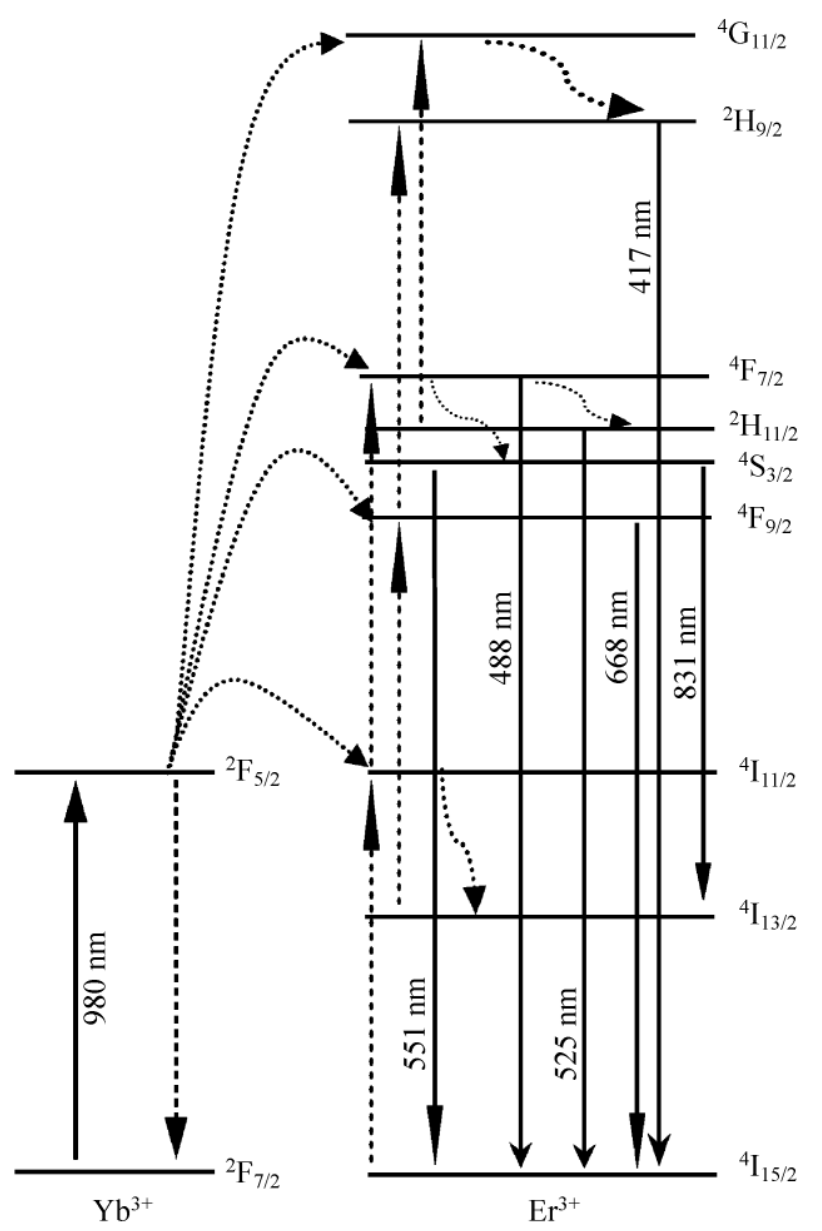

Figure 6 Scheme showing the mechanism of upconversion luminescence
IR photons absorbed per emission photon as shown in the following formula: $\ln I_{\mathrm{o}} \propto n \cdot \ln I_{\mathrm{IR}}$ [25]. As shown in Fig. 7, the slopes of the plots $(n)$ are 1.92 and 2.11 for the green $(551 \mathrm{~nm})$ and red $(668 \mathrm{~nm})$ emissions, respectively. These double logarithmic plots of the visible upconversion emission intensity versus the power density of the $980 \mathrm{~nm}$ excitation confirm that both the 551 and $668 \mathrm{~nm}$ emissions involve two-photon upconversion processes. At high excitation densities the slope of the curves is reduced due to upconversion process saturation [31]. However, for the NIR (831 nm) emission of the PAA-coated nanoparticles, the slope of the plot is 2.71 , which indicates that the upconversion emission is a three-photon process. Because of the strong chelating effect of PAA, the nanoparticle surface is coated with PAA molecules, as shown by TEM and FTIR spectroscopy. Due to the high vibrational frequency of $-\mathrm{COOH}$ and $-\mathrm{OH}$ groups in the PAA moieties coated on the nanoparticle surface, crossrelaxation is significant, and this might be responsible for the NIR emission [27]. More detailed research into the exact cause of the NIR emission is still underway.

\section{Conclusions}

We have successfully prepared luminescent $\mathrm{YF}_{3}: \mathrm{Yb}^{3+} / \mathrm{Er}^{3+}$ nanorice and $\mathrm{YF}_{3}: \mathrm{Yb}^{3+} / \mathrm{Er}^{3+} @ \mathrm{PAA}$ nanoparticles by using different surfactants. In the absence of PAA as a

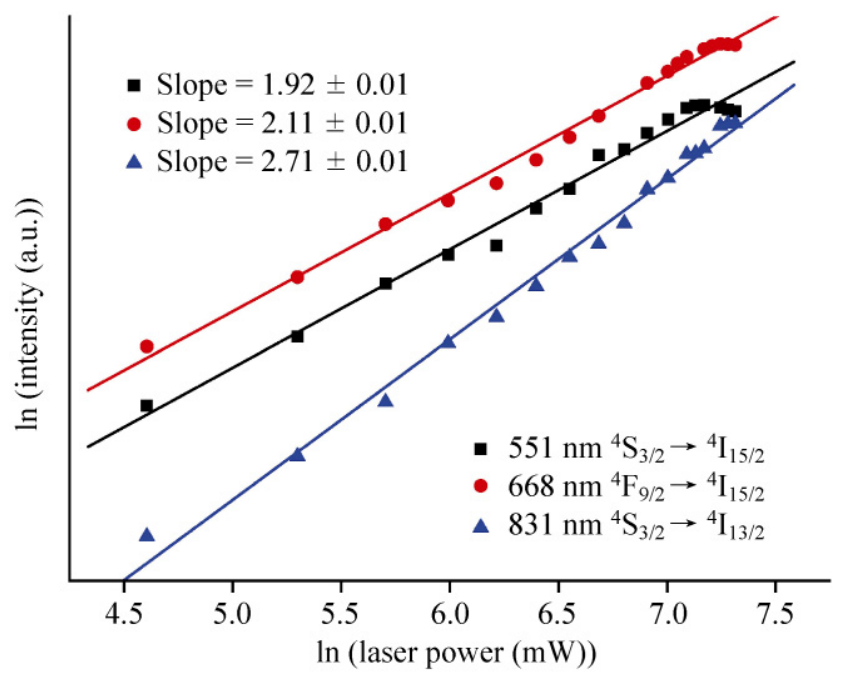

Figure 7 Power dependence of the upconversion luminescence of the $\mathrm{YF}_{3}: \mathrm{Yb}^{3+} / \mathrm{Er}^{3+} @$ PAA nanoparticles (ム) and $\mathrm{YF}_{3}: \mathrm{Yb}^{3+} / \mathrm{Er}^{3+}$ nanorice $(\bullet$ and $\mathbf{\bullet})$ excited at $980 \mathrm{~nm}$ 
surfactant, only large nanorice particles were obtained. These nanorice particles are very large $(\sim 700 \mathrm{~nm}$ in length) and show strong red upconversion fluorescence visible to the naked eye. However, in the presence of PAA as a surfactant, nanoparticles with a uniform size of $\sim 50 \mathrm{~nm}$, good dispersibility, and a large number of surface carboxylate groups were obtained. Unlike the nanorice materials, these luminescent nanoparticles emit strong NIR (831 nm) upconverting luminescence at $980 \mathrm{~nm}$ excitation. This novel NIR upconversion luminescence and the carboxylate-coated surface make these nanoparticles good candidates for biolabeling applications, especially for deep in vivo imaging due to the deep penetration of NIR radiation into tissue. Upconversion imaging studies are underway and will be reported elsewhere and suggest that these novel nanophosphors are promising candidates for applications as active components for fluorescence immunoassays, cell imaging, and especially as fluorescent labels for in vivo imaging with deep penetration.

\section{Acknowledgements}

We acknowledge the financial support from the National Natural Science Foundation of China (Nos. 20605001 and 20871004) and start-up funding of Beijing University of Chemical Technology.

Electronic Supplementary Material: SEM images of nanoparticles prepared using PAA, PEG and SDS as the surfactants are available in the online version of this article at http://dx.doi.org/10.1007/s12274-010-1035-z and are accessible free of charge.

Open Access: This article is distributed under the terms of the Creative Commons Attribution Noncommercial License which permits any noncommercial use, distribution, and reproduction in any medium, provided the original author(s) and source are credited.

\section{References}

[1] Ge, J. P.; Hu, Y. X.; Biasini, M.; Beyermann, W. P.; Yin, Y. D. Superparamagnetic magnetite colloidal nanocrystal clusters. Angew. Chem. Int. Edit. 2007, 46, 4342-4345.
[2] Wang, L. Y.; Yang, Z. H.; Zhang, Y.; Wang, L. Bifunctional nanoparticles with magnetization and luminescence. J. Phys. Chem. C 2009, 113, 3955-3959.

[3] Hill, H. D.; Hurst, S. J.; Mirkin, C. A. Curvature-induced base pair "slipping" effects in DNA-nanoparticle hybridization. Nano Lett. 2009, 9, 317-321.

[4] Bruchez, M.; Moronne, M.; Gin, P.; Weiss, S.; Alivisatos, A. P. Semiconductor nanocrystals as fluorescent biological labels. Science 1998, 281, 2013-2016.

[5] Chan, W. C. W.; Nie, S. M. Quantum dot bioconjugates for ultrasensitive nonisotopic detection. Science 1998, 281, 2016-2018.

[6] Gao, X. H.; Cui, Y. Y.; Levenson, R. M.; Chung, L. W. K.; Nie, S. M. In vivo cancer targeting and imaging with semiconductor quantum dots. Nat. Biotechnol. 2004, 22, 969-976.

[7] Viswanatha, R.; Battaglia, D. M.; Curtis, M. E.; Mishima, T. D.; Johnson, M. B.; Peng, X. Shape control of doped semiconductor nanocrystals (d-dots). Nano Res. 2008, 1, 138-144.

[8] Sivakumar, S.; Diamente, P. R.; van Veggel, F. C. Silicacoated $\mathrm{Ln}^{3+}$-doped $\mathrm{LaF}_{3}$ nanoparticles as robust down- and upconverting biolabels. Chem. -Eur. J. 2006, 12, 5878-5884.

[9] Santra, S.; Yang, H.; Dutta, D.; Stanley, J. T.; Holloway, P. H.; Tan, W. H.; Moudgil, B. M.; Mericle, R. A. TAT conjugated, FITC doped silica nanoparticles for bioimaging applications. Chem. Commun. 2004, 2810-2811.

[10] Wang, L. Y.; Li, Y. D. Green upconversion nanocrystals for DNA detection. Chem. Commun. 2006, 2557-2559.

[11] Yezhelyev, M. V.; Qi, L.; Regan, R. M. O.; Nie, S.; Gao, X. Proton-sponge coated quantum dots for siRNA delivery and intracellular imaging. J. Am. Chem. Soc. 2008, 130, 9006-9012.

[12] Mancini, M. C.; Kairdolf, B. A.; Smith, A. M.; Nie, S. Oxidative quenching and degradation of polymer-encapsulated quantum dots: New insights into the long-term fate and toxicity of nanocrystals in vivo. J. Am. Chem. Soc. 2008, 130, 10836-10837.

[13] King-Heiden, T. C.; Wiecinski, P. N.; Mangham, A. N.; Metz, K. M.; Nesbit, D.; Pedersen, J. A.; Hamers, R. J.; Heideman, W.; Peterson, R. E. Quantum dot nanotoxicity assessment using the zebrafish embryo. Environ. Sci. Technol. 2009, 43, 1605-1611.

[14] Gouveia-Neto, A. S.; da Costa, E. B.; Bueno, L. A; Ribeiro, S. J. L. Intense red upconversion emission in infrared excited holmium-doped $\mathrm{PbGeO}_{3}-\mathrm{PbF}_{2}-\mathrm{CdF}_{2}$ transparent glass ceramic. J. Lumin. 2004, 110, 79-84.

[15] Wang, L. Y.; Li, Y. D. $\mathrm{Na}\left(\mathrm{Y}_{1.5} \mathrm{Na}_{0.5}\right) \mathrm{F}_{6}$ single-crystal nanorods as multicolor luminescent materials. Nano Lett. 2006, 6, 1645-1649. 
[16] Yi, G. S.; Lu, H. C.; Zhao, S. Y.; Yue, G.; Yang, W. J.; Chen, D. P.; Guo, L. H. Synthesis, characterization, and biological application of size-controlled nanocrystalline $\mathrm{NaYF}_{4}$ : $\mathrm{Yb}$, Er infrared-to-visible up-conversion phosphors. Nano Lett. 2004, 4, 2191-2196.

[17] Wang, L. Y.; Yan, R. X.; Hao, Z. Y.; Wang, L.; Zeng, J. H.; Bao, J.; Wang, X.; Peng, Q.; Li, Y. D. Fluorescence resonant energy transfer biosensor based on upconversion-luminescent nanoparticles. Angew. Chem. Int. Edit. 2005, 44, 6054-6057.

[18] van de Rijke, F.; Zijlmans, H.; Li, S.; Vail, T.; Raap, A. K.; Niedbala, R. S.; Tanke, H. J. Up-converting phosphor reporters for nucleic acid microarrays. Nat. Biotechnol. 2001, 19, 273-276.

[19] Yan, R. X.; Li, Y. D. Down/up conversion in $\mathrm{Ln}^{3+}$-doped $\mathrm{YF}_{3}$ nanocrystals. Adv. Funct. Mater. 2005, 15, 763-770.

[20] Heer, S.; Kompe, K.; Gudel, H. U.; Haase, M. Highly efficient multicolour upconversion emission in transparent colloids of lanthanide-doped $\mathrm{NaYF}_{4}$ nanocrystals. Adv. Mater. 2004, 16, 2102-2104.

[21] Gao, L.; Ge, X.; Chai, Z.; Xu, G.; Wang, X.; Wang, C. Shapecontrolled synthesis of octahedral $\alpha-\mathrm{NaYF}_{4}$ and its rare earth doped submicrometer particles in acetic acid. Nano Res. 2009, 2, 565-574.

[22] Yu, X.; Li, M.; Xie, M.; Chen, L.; Li, Y.; Wang, Q. Dopant-controlled synthesis of water-soluble hexagonal $\mathrm{NaYF}_{4}$ nanorods with efficient upconversion fluorescence for multicolor bioimaging. Nano Res. 2010, 3, 51-60.

[23] Mai, H. X.; Zhang, Y. W.; Si, R.; Yan, Z. G.; Sun, L. D.; You, L. P.; Yan, C. H. High-quality sodium rare-earth fluoride nanocrystals: Controlled synthesis and optical properties. $J$.
Am. Chem. Soc. 2006, 128, 6426-6436.

[24] Wang, L. Y.; Li, P.; Li, Y. D. Down- and up-conversion luminescent nanorods. Adv. Mater. 2007, 19, 3304-3307.

[25] Boyer, J. C.; Cuccia, L. A.; Capobianco, J. A. Synthesis of colloidal upconverting $\mathrm{NaYF}_{4}: \mathrm{Er}^{3+} / \mathrm{Yb}^{3+}$ and $\mathrm{Tm}^{3+} / \mathrm{Yb}^{3+}$ monodisperse nanocrystals. Nano Lett. 2007, 7, 847-852.

[26] Boyer, J. C.; Vetrone, F.; Cuccia, L. A.; Capobianco, J. A. Synthesis of colloidal upconverting $\mathrm{NaYF}_{4}$ nanocrystals doped with $\mathrm{Er}^{3+}, \mathrm{Yb}^{3+}$ and $\mathrm{Tm}^{3+}, \mathrm{Yb}^{3+}$ via thermal decomposition of lanthanide trifluoroacetate precursors. J. Am. Chem. Soc. 2006, 128, 7444-7445.

[27] Wang, Y.; Tu, L.; Zhao, J.; Sun, Y.; Kong, X.; Zhang, H. Upconversion luminescence of $\beta-\mathrm{NaYF}_{4}: \mathrm{Yb}^{3+}, \mathrm{Er}^{3+} @ \beta-\mathrm{NaYF}_{4}$ core/shell nanoparticles: Excitation power density and surface dependence. J. Phys. Chem. C 2009, 113, 7164-7169.

[28] Schafer, H.; Ptacek, P.; Zerzouf, O.; Haase, M. Synthesis and optical properties of $\mathrm{KYF}_{4} / \mathrm{Yb}$, Er nanocrystals, and their surface modification with undoped $\mathrm{KYF}_{4}$. Adv. Funct. Mater. 2008, 18, 2913-2918.

[29] Grogan, M. J.; Kaizuka, Y.; Conrad, R. M.; Groves, J. T.; Bertozzi, C. R. Synthesis of lipidated green fluorescent protein and its incorporation in supported lipid bilayers. $J$. Am. Chem. Soc. 2005, 127, 14383-14387.

[30] Capobianco, J. A.; Vetrone, F.; Boyer, J. C.; Speghini, A.; Bettinelli, M. Enhancement of red emission $\left({ }^{4} \mathrm{~F}_{9 / 2}{ }^{4} \mathrm{I}_{15 / 2}\right)$ via upconversion in bulk and nanocrystalline cubic $\mathrm{Y}_{2} \mathrm{O}_{3}: \mathrm{Er}^{3+}$. J. Phys. Chem. B 2002, 106, 1181-1187.

[31] Suyver, J. F.; Aebischer, A.; Garcia-Revilla, S.; Gerner, P.; Gudel, H. U. Anomalous power dependence of sensitized upconversion luminescence. Phys. Rev. B 2005, 71, 125123. 